\title{
Social Norms and Engagement in Protective Health Behaviors Among Rural Health Providers
}

\author{
Danielle L. Terry ${ }^{1}$ (D) David P. Mathews ${ }^{1,2}$
}

Accepted: 5 January 2022 / Published online: 20 January 2022

(c) The Author(s), under exclusive licence to Springer Science+Business Media, LLC, part of Springer Nature 2022

\begin{abstract}
The COVID-19 pandemic has had far-reaching effects for individuals and healthcare systems in the United States. Increasing and sustaining behavioral changes to reduce transmission of disease among medical providers is essential for the protection of the community at large. Using a social norms perspective, this study aimed to (a) examine the accuracy of perceptions of engagement in protective health behaviors among a sample of rural health providers, and (b) determine whether greater self-other discrepancies were associated with engagement in these behaviors. Electronic surveys were completed by 214 rural medical providers. Findings suggested that rural healthcare providers had exaggerated perceptions of peer engagement in several COVID-19-related protective health behaviors. As expected, positive self-other differences were positively associated with providers' own behaviors, and perceived descriptive norms were associated with providers' engagement in these behaviors. Future studies using normative interventions might examine how positive self-other differences increase the use of protective health behaviors over time.
\end{abstract}

Keywords COVID-19 $\cdot$ Rural $\cdot$ Medical providers $\cdot$ Social norms

On March 11, 2020, the World Health Organization declared a pandemic resulting from an outbreak of Coronavirus disease 2019 (COVID-19). Caused by the severe acute respiratory syndrome coronavirus 2 (SARS-CoV-2) and spread primarily through respiratory droplets, COVID-19 is associated with a range of symptoms and complications, including fever, cough, pneumonia, and death (Centers for Disease Control \& Prevention, 2020a, 2020d). The COVID-19 pandemic has had far-reaching effects for individuals and healthcare systems in the United States and across the globe. In many areas of the United States, projected rates of infection have threatened to cause shortages in available medical equipment and personnel. The response has been the adoption of nation-wide measures aiming to "flatten the curve," or reduce the number of new infections. Even then, a "new normal" has effectively been established for those working in healthcare.

Danielle L. Terry

Danielle.terry@guthrie.org

1 Guthrie Medical Group, One Guthrie Square, Sayre, PA 18840, USA

2 Binghamton University, Binghamton, NY, USA
In addition to governmental regulations (Centers for Disease Control \& Prevention, 2020c), national and local health agencies have urged residents to adjust their everyday behaviors and adopt habits that could slow the spread of the virus. Recommended practices to reduce transmission of COVID-19 include isolation and/or reduced contact with other individuals. Specifically, Centers for Disease Control and Prevention (Centers for Disease Control \& Prevention, 2020c) recommends washing one's hands often, wearing face masks, and maintaining six feet of distance between oneself and others (i.e., "social distancing"). Individuals are also encouraged to limit travel outside of their home communities as much as possible.

Healthcare workers have been expected to adopt a set of practices that have fundamentally impacted their workflow. Systems were required to adapt to changes in patient scheduling and interactions, and providers were encouraged to utilize telehealth platforms (Centers for Disease Control \& Prevention, 2020b, 2020e). Stringent standards were established to triage patients who presented symptoms of COVID-19, whether they be severe or minor. Healthcare workers were expected to follow full "airborne precautions" when caring for patients suspected of having COVID-19. These precautions strongly encouraged the use of personal protective 
equipment (PPE) including goggles, N95 respirators, gloves, and isolation gowns. Finally, public health agencies published informational videos, encouraged completion of online courses, and provided links to online "webinars" for the purpose of teaching new health procedures. Health agencies were particularly insistent that providers practice the proper donning (putting on) and doffing (taking off) of PPE.

Given the rapid spread of the disease and its significant impact on healthcare settings, it has proven necessary to expedite the adoption of these health practices. Shortages developed in hospitals overwhelmed by the massive influx of patients, but they were also felt in areas that already suffered from provider shortages at a baseline. Prior to the pandemic, rural areas had consistently suffered from staffing shortages due to maldistribution of medical providers within the country (Weinhold \& Gurtner, 2014). In addition, supply and provider shortages have been complicated by COVID-19's long incubation period. Initial CDC recommendations suggested that medical providers isolate themselves for 14 days in the event of prolonged close contact with an infected patient. For all of these reasons, prevention-oriented behavioral changes among providers at risk of exposure have proven essential in managing the spread of COVID-19.

In order to encourage adherence to healthcare guidelines, it may be useful to determine what motivates individuals to act in accordance with recommended guidelines. Both the Theory of Planned Behavior (TPB) and the Theory of Reasoned Action (TRA) posit that an individual's attitude toward a behavior and perceived social norms surrounding the behavior contribute to an individual's intention, or motivation to carry out the behavior (Ajzen, 1985; Fishbein \& Ajzen, 1975). Attitude toward the behavior refers to positive and negative evaluations surrounding the behavior. In the context of COVID-19, these theories would suggest that the perceived risk of contracting the illness or experiencing negative health outcomes would affect one's attitude toward specific health behaviors (handwashing, use of personal protective equipment, etc.). The TPB also considers one's perceived behavioral control to be a major influence on intention (Ajzen, 1985). In other words, if an individual felt it would be very difficult to affect any meaningful change, he/she might have less motivation to engage in a specific behavior.

The TPB also suggests that perceptions of others' behaviors or attitudes (i.e., normative perceptions) influence one's own behaviors. Normative perceptions can be delineated into injunctive and descriptive norms. Simply stated, one's motivation is affected by whether they think others approve or disapprove of the behavior (injunctive norms; Ajzen, 1985; Fishbein \& Ajzen, 1975) or how often one believes his or her peers engage in that behavior (descriptive norms; Perkins \& Berkowitz, 1986). Self-other discrepancies (SODs) describe the perceived difference between one's personal attitudes and habits and those of their peers. Individuals may misjudge injunctive and descriptive norms, believing peers perform a behavior more often than they actually do. This misperception subsequently affects the individual's own behavior. That is, people who believe that others are more accepting of a behavior and/or engage in it more often are more likely to engage in it themselves. If someone has a positive selfother difference, he/she misperceives that others engage in a behavior more often than he/she does and also believes others find it more favorable. Conversely, if someone has a negative self-other difference, there is a misperception that others engage in a behavior less often and hold less favorable attitudes or opinions than the referencing individual.

Studies conducted on a number of behaviors have proven the predictive value of perceived social norms and SODs in determining an individual's behavior. For example, greater positive self-other differences led to increased alcohol consumption over time in a sample of college students (Carey et al., 2006). A number of factors can influence the size of alcohol-related SODs, including norm type (i.e., injunctive vs. descriptive), gender, and reference group (e.g., close friends vs. "typical student"; Borsari \& Carey, 2003). Larimer and Neighbors (2003) extended the theory to gambling, finding that perceived injunctive and descriptive norms predict how frequently an individual gambles, how much he/she spends, and how many negative consequences he/she experiences.

Terry and Terry (2016) offered potential insight into the interplay between perceived risk and social norms, finding that college students were more likely to text behind the wheel than drive while intoxicated, despite viewing the two behaviors as similarly risky. Students felt their peers were more accepting of the former, potentially contributing to this apparent discrepancy. These findings highlight the need to examine perceived risk and social norms when understanding behavioral intention.

Social norms interventions have been developed to help individuals increase and decrease the frequency of engagement in specific behaviors. The effectiveness of such interventions is perhaps the strongest evidence that social norms do indeed influence behavior. Gerber and Rogers (2009) found that, among those who vote infrequently or occasionally, intention to vote was directly positively influenced by a pre-election phone call claiming that high voter turnout was expected (i.e., many of one's peers would be voting). Other interventions have found a similar effect, including ones aiming to reduce alcohol use (e.g., Neighbors et al., 2010), decrease bullying behavior among children (Perkins et al., 2011), increase recycling and proenvironmental behavior, (e.g., Huber et al., 2020; Schultz, 1999) and even increase tax compliance (Wenzel, 2005). 
Being able to increase and sustain behavioral changes to reduce transmission of disease among medical providers is essential for the protection of the community at large. This study aimed to (a) examine the accuracy of perceptions of engagement in protective health behaviors among a sample of rural health providers, and (b) determine whether greater SODs were associated with engagement in these behaviors. It was hypothesized that, consistent with other areas of research, positive SODs and perceived risk would be significantly associated with self-reported engagement in protective health behaviors.

\section{Methods}

Surveys were sent to 690 medical providers working at rural Pennsylvania teaching hospital and associated satellite clinics. Providers were surveyed anonymously using Google Forms $@$. All procedures were approved by the Institutional Review Board of the associated hospital. The survey was initially sent to providers on March 30, 2020, 10 days following administrative directives to cancel routine care appointments within the organization. Prompts to complete the survey were sent 1 and 2 weeks later. The survey included questions about demographic information, perception of risk, engagement in protective health behaviors related to COVID-19, and respondents' perceptions of others engagement in those behaviors.

Demographic information included questions about gender, age, race/ethnicity, medical specialty, and years in practice. Medical providers were also asked to estimate the amount of time per week they spent consuming COVID19-related information or engaging in discussion surrounding COVID-19. They also responded to one question about their perceived risk of contracting COVID-19 which featured responses ranging from 1 (no risk) to 5 (high risk). One additional question about perceived control was included from the Perceived Stress Scale, 4-item (Cohen \& Kamarch, 1983).

Safety behaviors assessed included handwashing, encouraging patients to reschedule routine appointments, using PPE, triaging high-risk patients to minimize exposure to COVID, completing training activities (like doffing and donning), social distancing, and limiting travel. Respondents were asked to complete questions rating whether they increased their engagement in specific health behaviors over the past 2 weeks. Items were rated on a Likert scale from 1 [same as usual (before pandemic)] to 5 (significantly increased). Questions assessing descriptive norms for others paralleled personal frequency estimates, a precedent established in other studies (Park \& Smith, 2007). All response options were identical to those asking about respondents' personal estimates of safety behaviors and asked about respondents' change in behavior since the onset of the pandemic.

Data were analyzed using SPSS Version 25 (SPSS Inc/ IMB, Chicago, IL). Descriptive statistics were used to examine sample characteristics, and multiple linear regression was used to look at associations between perceived norms and estimates of actual behavior following onset of the pandemic.

Self-other differences for descriptive and injunctive norms were calculated by taking the difference (i.e., subtracting the responses) between norms endorsed by the participant and perceived norms held by others. All seven protective health behaviors were examined using multiple linear regression. All analyses included the norm of interest (i.e., the specific health behavior), perception of risk, and perceived control over the work environment in order to factor in variables included in the TPB.

\section{Results}

Participants included 214 medical providers (31\% response rate) working at a rural medical organization in the northeast. Respondents were primarily female $(58.4 \%, n=125)$ and identified as white $(87.2 \%, n=184)$ followed by Asian or Pacific Islander $(7 \%, n=15)$. They were an average of $47.9(S D=11.9)$ years old and had worked as a medical provider for an average of $15.9(S D=11.0)$ years. Providers were from a variety of different specialties and subspecialties including family and internal medicine $(40.5 \%, n=87)$, surgery $(8.8 \%, n=19)$, and radiology $(5.1 \%, n=11)$. A total of 27 other specialties were identified, and each constituted $.5 \%$ to $4.2 \%$ of the sample. The representation of medical providers who responded to the survey was similar to the overall organization (58.5\% MD/DO). However, it was notable that there was an over-representation of providers who identified as white $(82.2 \%$ versus national estimates of 56.2\%; (Association of American Medical Colleges, 2019). See Table 1 for a list of participant characteristics. See Table 2 for a summary of findings below.

\section{Perceived Norms}

Participants thought that their peers encouraged patients to reschedule appointments more often than they did themselves, $t(205)=-2.30, p=.02, d=.16$. They believed that peers had a greater increase in the amount they completed training activities, like doffing and donning, following onset of the pandemic, as compared to themselves $t(207)=-3.85, p=.00, d=.27$. In addition, they believed peers had increased their practice of social distancing more than they had, $t(210)=7.01, p=.00, d=.48$, and had limited their travel more extensively, $t(208)=6.47, p=.00, d=.45$. 
Table 1 Demographic information $(N=214)$

\begin{tabular}{|c|c|c|c|}
\hline Characteristics & $n$ & $M(S D)$ & $\%$ \\
\hline Age & 169 & $47.8(11.9)$ & - \\
\hline \multicolumn{4}{|l|}{ Gender } \\
\hline Female & 125 & - & 58.4 \\
\hline Male & 89 & - & 41.6 \\
\hline Trans/nonbinary & 0 & - & - \\
\hline \multicolumn{4}{|l|}{ Profession } \\
\hline Physician* & 109 & & 51.2 \\
\hline Physician assistant & 27 & & 12.7 \\
\hline Nurse practitioner & 66 & & 31.0 \\
\hline Other** & 11 & & 5.2 \\
\hline \multicolumn{4}{|l|}{ Race/Ethnicity } \\
\hline American Indian & 1 & - & .5 \\
\hline Asian & 15 & - & 7.1 \\
\hline African American & 3 & - & 1.4 \\
\hline Hispanic/Latino & 3 & - & 1.4 \\
\hline White/Caucasian & 184 & - & 87.2 \\
\hline Other & 5 & - & 2.4 \\
\hline \# Years in practice & 211 & $15.9(11.0)$ & - \\
\hline \multicolumn{4}{|l|}{ Specialty } \\
\hline Family medicine & 57 & - & 27.5 \\
\hline Internal medicine & 30 & - & 14.5 \\
\hline Pediatrics & 12 & - & 5.8 \\
\hline Radiology & 11 & - & 5.1 \\
\hline Surgery & 19 & - & 9.2 \\
\hline Other $* * *$ & 96 & & 37.9 \\
\hline
\end{tabular}

* $1.9 \%$ of physicians also identified as medical residents

**Other professionals included psychologists, audiologists, and occupational therapists

***Other specialties included 27 other categories in addition to those listed. Those not listed comprised $5 \%$ of the sample or less

Table 2 Regression analysis summary for other's perceived safety behaviors predicting self-reported practices

\begin{tabular}{lccc}
\hline Variable & $\beta$ & \multicolumn{1}{l}{$t$} & \multicolumn{1}{l}{$p$} \\
\hline Handwashing & .22 & 2.92 & .004 \\
Rescheduling appointments & .44 & 6.93 & .000 \\
Use of PPE* & .33 & 5.12 & .000 \\
Triaging patients to reduce risk & .38 & 6.10 & .000 \\
Engagement in training activities & .63 & 12.33 & .000 \\
Use of social distancing & .23 & 3.53 & .001 \\
Limiting travel & .18 & 2.43 & .000 \\
\hline
\end{tabular}

*Personal protective equipment

\section{Handwashing}

Multiple linear regression was calculated to predict change in handwashing behavior after onset of the pandemic based on perception of risk and perceived norms while controlling for perceived control within one's environment. A significant regression equation was found $F(3,205)=6.05$, $p<.01, R=.08$ ). Analyses indicated that perception of risk predicted self-reported changes in handwashing behavior, $\beta=.22, t(208)=2.92, p=.004$. Perceived norms of handwashing behavior was associated with handwashing behavior, $\beta=.26, t(208)=2.97, p=.003$.

\section{Rescheduling Appointments}

The overall regression model testing whether perceived risk and perceived norms predicted rescheduling of non-essential appointments was significant, $F(3,204)=17.39, p=.00$, $R=.206$. Analyses suggested that perceived norms related to peers' practice of rescheduling non-essential appointments was an independent predictor of one's own behavior, $\beta=.44$, $t(204)=6.93, p=.000$.

\section{Use of PPE}

Multiple linear regression analysis explored whether use of PPE was predicted by perceived norms and perceived risk while controlling for perceived control. A significant regression model was found, $F(3,210)=13.97, p=.00$, $R=.17$. Perceived norms independently predicted use of PPE, $\beta=.33, t(210)=5.12, p=.00$ as did perceived risk, $\beta=.23, t(210)=3.59, p=.00$.

\section{Triaging Patients to Reduce Risk}

Multiple linear regression analysis explored whether triaging high-risk patients was predicted by perceived norms and perceived risk while controlling for perceived control. A significant regression model was found $F(3,203)=18.29$, $p=.00, R=.22$. Perceived norms independently predicted triaging high-risk patients, $\beta=.38, t(203)=6.10, p=.00$, as did perceived risk, $\beta=.21, t(203)=3.26, p=.00$.

\section{Engagement in Training Activities}

The overall regression model testing whether perceived risk and perceived norms predicted engagement in training activities related to COVID-19 was significant, $F$ (3, 206) $=62.95, p=.00, R=.48$. Analyses suggested that both perception of risk, $\beta=.21, t(206)=4.08, p=.00$, and perceived norms, $\beta=.63, t(206)=12.33, p=.00$ significantly predicted engagement in training activities.

\section{Use of Social Distancing}

Multiple linear regression analysis explored whether respondents' adherence to social distancing guidelines was 
predicted by perceived norms and perceived risk while controlling for perceived control. A significant regression model was found, $F(3,209)=9.80, p=.00, R=.13$. Analyses suggested that both perception of risk, $\beta=.25, t(209)=3.79$, $p=.00$, and perceived norms, $\beta=.23, t(209)=3.53, p=.001$ were significant predictors of use of social distancing.

\section{Limits on Travel}

Finally, multiple linear regression analysis was used to determine whether provider's self-imposed limits on travel was predicted by perceived norms and perceived risk. A significant regression model was found $F(3,207)=3.56, p=.02$, $R=.05$. Perception of risk did not independently predict selfreported limitations on travel, $\beta=.11, t(207)=1.66, p=.12$. Perceived norms independently predicted limitations on travel, $\beta=.18, t(207)=2.43, p=.00)$.

\section{Discussion}

This study aimed to (a) examine the accuracy of perceptions of engagement in protective health behaviors among a sample of rural health providers, and (b) determine whether greater SODs were associated with engagement in these behaviors, consistent with other areas of research.

Primary hypotheses in this study were supported. Findings suggested that rural healthcare providers had exaggerated perceptions of peer engagement in several COVID19-related protective health behaviors, as compared to the sample's self-reported practices. Specifically, they believed their peers rescheduled appointments, participated in training, adhered to social distancing guidelines, and limited travel more than they themselves had. Moreover, the association with social norms was significant for all seven health behaviors studied. As expected, these positive self-other differences were positively associated with providers' own behaviors, and perceived descriptive norms were associated with providers' engagement in these behaviors. That is, those with exaggerated perceptions, or positive self-other differences, tended to practice protective health behaviors more.

These findings have several important implications. First, they expand upon similar findings in numerous other settings that indicate one's own behavior is positively associated with the perception of peer's behavior (Carey et al., 2006; Huber et al., 2020; Larimer \& Neighbors, 2003; Neighbors et al., 2010; Schultz, 1999; Wenzel, 2005) This aligns with social norms theories and the TPB, which suggest that perception of risk and perceived social norms are fundamental in intention and practice of specific behaviors.

Second, in the general population, opinions regarding use of protective health behaviors (i.e., use of face masks) have become increasingly polarized, and have arguably turned into a political and social issue (Smith, 2020; Wibawa, 2020). Given this trend, understanding ways in which to shift individuals' opinions on these life-saving behaviors using social norms may be helpful in identifying more subtle ways to influence protective behaviors among medical personnel and the larger community. Future research might investigate responses to interventions that aim to alter normative perceptions of safety behaviors using established normative intervention strategies (Miller \& Prentice, 2016). For example, social marketing strategies send blanketed messages targeting the reference group. Personalized normative feedback interventions provide information to the individual about how they perform in comparison to those around them, while group conversation strategies require that participants examine existing norms and practices and determine what the norms are among themselves.

With the resurgence of COVID-19 cases throughout the United States, and the unfortunate knowledge that the nation is not adequately prepared to handle viruses not previously known to humans, understanding the factors that impact medical personnel may be important to protect against current threats as well as future ones. Future studies using normative interventions for COVID-19 might examine how positive self-other differences increase the use of protective health behaviors over time. In the case of other health behaviors, such as alcohol use, longitudinal studies show that positive self-other difference may "draw up" the behavior over time (Perkins, 2002). This may be particularly important for behaviors that are difficult to sustain once an individual habituates to the anxiety, as with a disease that becomes better contained. For example, as individuals within society begin to engage in usual activities, and as businesses reopen (https://www.whitehouse.gov/openingamerica/), the perception that others are engaging in specific protective health behaviors may shift. Based on other research related to social norms, this perception may result in a reduction in the use of protective behaviors when it is not necessarily safe to do so.

\section{Limitations}

There were several limitations to this study. First, although the response rate was comparable to other electronic surveys (Cook et al., 2000; Phillips et al., 2017), online surveys are prone to several methodological limitations. These include low response rates and voluntary response bias, in which it was possible that only those who were most motivated (or felt the most passionate) about this topic completed the survey. Similarly, this study examines individuals that may be more adherent to safety practices than other populations. For example, other personnel who have essential contact 
with the community (e.g., mental health providers, support staff, grocery store employees) may be more appropriately targeted compared to medical providers, who are already practicing CDC recommendations as part of usual care. This survey was also correlational. Although findings were consistent with previous research, further longitudinal and interventional methodologies could be employed to examine whether use of social norms interventions might increase protective health behaviors over time.

Finally, any generalizations made from this study should recognize the over-representation of white providers. The sample from this study had a significantly higher proportion of individuals who identified as white compared to national data (Association of American Medical Colleges, 2019) In addition to an over-representation in comparison to national estimates, some research has suggested that providers who identify as racial or ethnic minorities may be more likely to work in rural or underserved areas (Xierali \& Nivet, 2018). Thus, our findings may be limited in their generalizability to other settings and populations.

\section{Declarations}

Conflict of interest Danielle L. Terry and David P. Mathews have no relevant financial or non-financial interests to disclose.

Human and Animal Rights and Informed Consent The study was approved by the Guthrie Institutional Review Board and was performed in accordance with the ethical standards as laid down in the 1964 Declaration of Helsinki and its later amendments or comparable ethical standards. Informed consent was obtained from all patients for being included in the study.

\section{References}

Ajzen, I. (1985). From intentions to actions: A theory of planned behavior. Action-control: From cognition to behavior (pp. 11-39). Springer.

Association of American Medical Colleges. (2019). Diversity in medicine: Facts and figures 2019. Retrieved from https://www. aamc.org/data-reports/workforce/interactive-data/figure-18percentage-all-active-physicians-race/ethnicity-2018

Borsari, B., \& Carey, K. B. (2003). Descriptive and injunctive norms in college drinking: A meta-analytic integration. Journal of Studies on Alcohol. Journal of Studies on Alcohol, 64, 331-341.

Carey, K. B., Borsari, B., Carey, M. P., \& Maisto, S. A. (2006). Patterns and importance of self-other differences in college drinking norms. Psychology of Addictive Behaviors, 20, 385-393. https://doi.org/10.1037/0893-164X.20.4.385

Centers for Disease Control and Prevention. (2020a). Cases and deaths in the U.S. Retrieved from https://www.cdc.gov/coron avirus/2019-ncov/cases-updates/us-cases-deaths.html

Centers for Disease Control and Prevention. (2020b). Guidance for U.S. healthcare facilities about coronovirus (COVID-19).
Retrieved from https://www.cdc.gov/coronavirus/2019-ncov/ hcp/us-healthcare-facilities.html

Centers for Disease Control and Prevention. (2020c). How to protect yourself and others. Retrieved from https://www.cdc.gov/coron avirus/2019-ncov/prevent-getting-sick/prevention.html

Centers for Disease Control and Prevention. (2020d). Symptoms of coronavirus. Retrieved from https://www.cdc.gov/coronavirus/ 2019-ncov/symptoms-testing/symptoms.html

Centers for Disease Control and Prevention. (2020e). Using personal protective equipment (PPE). Retrieved from https://www.cdc.gov/ coronavirus/2019-ncov/hcp/using-ppe.html

Cohen, S. T., \& Kamarch, R. (1983). A global measure of perceived stress. Journal of Health and Social Behavior, 24, 385-396.

Cook, C., Heath, F., \& Thompson, R. L. (2000). A meta-analysis of response rates in web- or Internet-based surveys. Educational and Psychological Measurement, 30, 821-833. https://doi.org/ 10.1177/00131640021970934

Fishbein, M., \& Ajzen, I. (1975). Belief, attitude, intention, and behavior: An introduction to theory and research. Addison-Wesley.

Gerber, A. S., \& Rogers, T. (2009). Descriptive social norms and motivation to vote: Everybody's voting and so should you. The Journal of Politics, 71, 178-191. https://doi.org/10.1017/S0022 381608090117

Huber, J., Viscusi, W. K., \& Bell, J. (2020). Dynamic relationships between social norms and pro-environmental behavior: Evidence from household recycling. Behavioural Public Policy, 4, 1-25. https://doi.org/10.1017/bpp.2017.13

Larimer, M. E., \& Neighbors, C. (2003). Normative misperception and the impact of descriptive and injunctive norms on college student gambling. Psychology of Addictive Behaviors, 17, 235-243. https://doi.org/10.1037/0893-164X.17.3.235

Miller, D. T., \& Prentice, D. A. (2016). Changing norms to change behavior. Annual Review of Psychology, 67, 339-361. https://doi. org/10.1146/annurev-psych-010814-015013

Neighbors, C., Lewis, M. A., Atkins, D. C., Jensen, M. M., Walter, T., Fossos, N., Lee, C. M., \& Larimer, M. E. (2010). Efficacy of webbased personalized normative feedback: A two-year randomized controlled trial. Journal of Consulting and Clinical Psychology, 78, 898-911. https://doi.org/10.1037/a0020766

Park, H. S., \& Smith, S. W. (2007). Distinctiveness and influence of subjective norms, personal descriptive and injunctive norms, and societal descriptive and injunctive norms on behavioral intent: A case of two behaviors critical to organ donation. Communication Research, 33, 194-218.

Perkins, H. W. (2002). Social norms and the prevention of alcohol misuse in collegiate contexts. Journal of Studies on Alcohol. https:// doi.org/10.15288/jsas.2002.s14.164

Perkins, H. W., \& Berkowitz, A. D. (1986). Perceiving the community norms of alcohol use among students: Some research implications for campus alcohol education programming. International Journal of the Addictions, 21, 961-967. https://doi.org/10.3109/ 10826088609077249

Perkins, H. W., Craig, D. W., \& Perkins, J. M. (2011). Using social norms to reduce bullying: A research intervention among adolescents in five middle schools. Group Processes \& Intergroup Relations, 14, 703-722. https://doi.org/10.1177/1368430210398004

Phillips, A. W., Friedman, B. T., Utrankar, A., Ta, A. Q., Reddy, S. T., \& Durning, S. J. (2017). Surveys of health professions trainees: Prevalence, response rates, and predictive factors to guide researchers. Academic Medicine, 92, 222-228. https://doi.org/10. 1097/ACM.0000000000001334

Schultz, P. W. (1999). Changing behavior with normative feedback interventions: A field experiment on curbside recycling. Basic and Applied Social Psychology, 21, 25-36. https://doi.org/10.1207/ s15324834basp2101_3 
Smith, T. (2020). The battle between the masked and the maskednots unveils political rifts. Retrieved from https://www.npr.org/ 2020/05/29/864515630/the-battle-between-the-masked-and-themasked-nots-unveils-political-rifts

Terry, C. P., \& Terry, D. L. (2016). Distracted driving among college students: Perceived risk versus reality. Current Psychology, 35, $115-120$

Weinhold, I., \& Gurtner, S. (2014). Understanding shortages of sufficient health care in rural areas. Health Policy, 118, 201-214.

Wenzel, M. (2005). Misperceptions of social norms about tax compliance: From theory to intervention. Journal of Economic Psychology, 26, 862-883. https://doi.org/10.1016/j.joep.2005.02.002

Wibawa, T. (2020). Wearing a mask in the United States is political, but Republicans are speaking out as coronavirus cases grow.
Retrieved from https://www.abc.net.au/news/2020-07-01/coron avirus-masks-are-political-in-us-donald-trump-rejects-them/ 12403962

Xierali, I. M., \& Nivet, M. A. (2018). The racial and ethnic composition and distribution of primary care physicians. Journal of Health Care for the Poor and Underserved, 29, 556-570. https://doi.org/ 10.1353/hpu.2018.0036

Publisher's Note Springer Nature remains neutral with regard to jurisdictional claims in published maps and institutional affiliations. 